\title{
Optimal Spending In A Private Foundation Given Known Parameters
}

\author{
Jeffry Haber, Iona College \& The Commonwealth Fund
}

\begin{abstract}
Private foundations are subject to an income tax of either $1 \%$ or $2 \%$ on their net investment income. The choice of whether to apply the $1 \%$ or $2 \%$ is based on a percentage derived by taking the funds expended divided by the asset base. If the percentage expended in the current year was greater than the average percentage for the last five years the foundation qualifies for the reduced percentage. Optimal spending is defined as the amount necessary to be expended in the current year to qualify for the reduced tax rate. The only accurate way to calculate the percentage is after the year is over (this can be somewhat modified if the foundation opts to use first-of-month values for their assets, instead of the more common end-of-month values). While accurate, this is not helpful for the private foundation that wishes to proactively try to qualify for the reduced percentage. Therefore, a number of assumptions must be made in performance of the calculation. This paper treats the assumptions as constants, based on the best estimate by an organization. Future research will lift this constraint, but as a first step in developing the literature on optimal spending, using known parameters is justified, and perhaps required.
\end{abstract}

\section{INTRODUCTION}

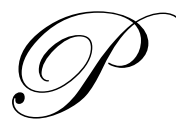

rivate foundations have an opportunity to cut their effective tax rate in half by increasing the percentage of dollars expended to assets under management as compared to the average of the previous five years. While greatly simplified, this gets at the heart of the matter. Complication will later be factored in, but as a start it is useful to know that most private foundations primarily exist based on the money provided by their investment return. Halving the tax, which occurs when the $2 \%$ rate is reduced to $1 \%$, is a worthwhile goal of the private foundation. A private foundation with a billion dollars in investments and a ten percent annual return can save $\$ 1,000,000$ in tax by using the reduced rate. Assuming the foundation closely monitors their required distribution, the tax savings will allow them to make more grants (the tax paid by the foundation is allowed to count toward their required distribution requirement, so less tax paid means that more grants have to be paid to meet the required distribution).

The percentage of funds expended to assets under management is easy to measure but hard to estimate and control. Once a private foundation authorizes a grant it is difficult to predict when the grantee will qualify to receive funds and in what amount. Most payment schemes are tied to deliverables, so a grantee that is late in submitting required materials will receive a payment later than anticipated. If this occurs at year-end, the cash disbursement will fall in the following year and not be a part of the funds distributed for the purpose of the calculation. While most financial reporting is done using the accrual system of accounting, the requisite qualifying for the reduced tax is done using the cash basis system of accounting. This adds an element of uncertainty to the calculation.

\section{THE FORMULA}

The formula used to calculate the optimal level of spending (that is, the minimal amount the private foundation has to expend to qualify for the reduced tax rate) is given by:

$[(\mathrm{ADP}+.000001) \times(.985 \times \mathrm{FMV})+(.01 \times(\mathrm{NII}-\mathrm{UG}))]-\mathrm{CDCP}-\mathrm{PRI}-\mathrm{CDAA} \leq 0$ 
The formula is divided into two sections. The first section (the section enclosed by the "[ ]") calculates the required qualifying cash disbursements necessary to receive the lower tax rate. The second section sums the elements of qualifying cash disbursements. The two sections are then subtracted - if the result is negative or zero, then the private foundation qualifies for the reduced percentage since the qualifying disbursements would have been greater than the required minimum.

\section{THE ELEMENTS OF THE FORMULA}

\section{Average Distribution Percentage}

The first element of the formula, the average distribution percentage for the past five years, is available from the current 990PF form (the annual tax return of a private foundation). This figure would be most accurate when it is based on the most recently filed 990PF form. In the event the average distribution percentage is required prior to filing the most recent tax return it can be estimated by taking the previous year's tax return, dropping the oldest of the five years and adding the projection for the current year as the newest of the five years, and recalculating the five year average.

\section{Applied Percentage Of Average Monthly Fair Market Value Of Assets}

The second element of the formula, the $98.5 \%$, which is applied to the average monthly fair market value of assets, is a constant and would only be adjusted when the statute or regulation changes.

\section{Average Monthly Fair Market Value Of Assets}

The third element, the average monthly fair market value of assets can be ascertained by either a strict estimate of what this would be for the year, or by taking the fair market value of assets at the beginning of the year and applying an expected monthly return to the assets, then averaging the twelve monthly ending asset values.

\section{Percentage Of Net Investment Income}

The fourth element of the formula, the $1 \%$ applied to net investment income, is a constant and would only be changed if statute or regulation changed.

\section{Net Investment Income}

The fifth element, the net investment income, can be derived by adding the monthly returns calculated above. These monthly returns are the expected month-to-month increase in the assets. 


\section{Unrealized Gains}

The sixth element is unrealized gains. Unrealized gains are not taxed, so the net investment income has to be reduced by the expected level of unrealized gains that are included in the monthly returns.

\section{Cash Disbursed For Charitable Purposes}

The seventh element, cash disbursed for charitable purposes, can be derived in a number of ways. One method would be to take all the expenditures that happen on a fixed schedule, such as payroll, payroll taxes, rent, utilities and insurance and estimate these for the year (unless known, then use the known amount). For other items, such as vendor bills that are not so predictable, use an estimate or take the beginning accounts payable, add the budgeted expenditures for the year and subtract the expected year-end accounts payable balance (or one month worth of payments).

\section{Program Related Investments}

The eighth element, program related investments, would be an estimate of the payments to be made that would qualify in this category.

\section{Cash Disbursed To Acquire Assets}

The ninth and final element, cash disbursed to acquire assets, would come from the organization's capital budget, and include the payments made to acquire capital assets. If no capital budget is used, an estimate can be used or the figure can be based on the past year's experience.

\section{APPLICATION AND SENSITIVITY ANALYSIS}

The formula specified by this paper is simplistic and easy to apply, even if the variables needed are not easy to estimate with accuracy. The goal of the formula is to present a target figure for achieving the reduced tax rate and allow the organization to decide whether that figure is in reasonable reach. Depending on an organization's structure and payment history, they can perform a sensitivity analysis with the formula.

The sensitivity analysis involves taking the formula and applying it under a few different scenarios. The scenarios will vary depending on the specifics of an organization. For instance, an organization that is largely invested in fixed income securities might feel very confident about the investment return (which factors into the average monthly assets), but not so good about the grant payments. They might hold all estimates constant except for the grant payments - they can apply the formula using their best estimate, then adjust that estimate up and down (two additional calculations) to form a band around their best estimate. This can be updated and refined during the course of the year and provide a decent plan for re-evaluating the achievability of the reduced tax rate.

An organization that has a better sense of their disbursements and less confidence in their investment returns (and hence less feel for what will be their average monthly assets) might want to apply the formula using a worst case, best case and best estimate for investment returns.

Applying the formula under a variety of assumptions also has the benefit of providing sensitivity analysis, that is, how much a change in a variable affects the final outcome. It may be for some organizations that a change in certain variables has no discernable affect on the outcome, thereby they can consider these elements constants and not spend time trying to control them. For the purposes of the formula they may just have virtually no effect. 


\section{FUTURE RESEARCH}

To be sure, the formula specified in this paper is based on point estimates for items that are continuous variables. To the extent that the best estimates provided by an organization are prescient is the extent to which this formula can be usable without modification or complication.

Since many private foundations are large, complex entities employing sophisticated investment tools, modification and complication might be required to make this formula useful. Future research will lift the point estimate constraint and include a robust selection of alternatives, perhaps probability distributions or confidence intervals.

\section{AUTHORS NOTE}

There is a spreadsheet that accompanies this paper that is an integral tool in aiding private foundations in determining the optimal spending level - please email the author for a copy, (jhaber@iona.edu).

\section{CONCLUSION}

Private foundations pay an excise tax of $1 \%$ or $2 \%$ of their net investment income. In simple terms, the deciding factor of whether to apply the $1 \%$ or $2 \%$ is based on a comparison of a percentage that is calculated by taking the current (tax) year's qualifying distributions and dividing by average monthly assets. In order to qualify for the reduced tax rate the current year's percentage has to be greater that the average percentage of the last five years.

The variables that go into the calculation are sometimes hard to estimate and control. Using a variety of scenarios the organization can perform a sensitivity analysis to help guide them through the year. Depending how the private foundation is structured in terms of investments and cash disbursement streams; they may find that certain variables have little effect on the outcome. They can treat these variables as constants and devote more time to projecting and controlling the other, more critical variables.

To be sure, point estimates for variables may not capture the necessary complexity demanded by the issue. Future research will develop estimations utilizing robust statistical processes to better reflect the variability inherent in projections required by the formula.

When all is said and done, the value of estimating the level of qualifying distributions necessary to qualify for the reduced tax is to provide a tool to the private foundation to allow them insight into how close (or far) they are from achieving the reduced tax. If very close, the private foundation can opt to make capital acquisitions in the current year to help ensure the reduced tax rate, or if not close, they can postpone year-end acquisitions to the beginning of the next year. This will both put more qualifying distributions in the next year and reduce the percentage expended in the current year (which will also make qualifying in the next year slightly easier). 